\title{
New Energy Power Generation and Their Application
}

\author{
Shengjun TIAN \\ Department of Electrical Engineering and Automation, North China Electric Power University , \\ Baoding, 071000, China \\ email: 2544122483@qq.com
}

Key words: solar energy, biogas, new energy

\begin{abstract}
Due to the low utilization efficiency of biogas, only a part of the family and farming enterprises use biogas to satisfy their need. So far, $60 \%$ of the equipment is idle, causing serious waste. In order to solve the problem, we combine biogas with a mew clean energy-solar energy, which is also much mature. A new percept named Photovoltaic complementary biogas power generation system is designed to improve resource utilization through using intelligent control. Meanwhile, the percept is much more stable and sustained than either of biogas power generation or solar panel alone.
\end{abstract}

\section{Preface}

In recent years, the state has attached great importance to agriculture, invested plenty of resources in energy conservation and staged series of policies to encourage using biogas[1]. In the national aquaculture enterprises, lots of biogas equipment has been installed. According to incomplete statistics, by 2015, the country has been completed 47 million large-scale biogas projects in poultry breeding farm. However, due to the low utilization efficiency of biogas, only a part of the family and farming enterprises use biogas to satisfy their need. So far, $60 \%$ of the equipment is idle, causing serious wastes [2]. The government encourages to development new energy now and new energy industry has become an inevitable trend of future energy development. Furthermore, in order to overcome the instability of biogas power generation, we use solar energy to make up. The field of complementary power generation combining biogas and solar energy remains blank. Therefore, this thesis focuses on the combination of biogas and solar energy in power generation technology. At the same time, we introduce the related research and application, promoting the development of new energy power generation industry.

\section{Power Generation by New Energy}

At present, on one hand, the livestock and poultry's waste is the main source of pollution in rural areas; on the other hand, the waste is an important raw material to produce biogas. Now the government encourages developing the biogas project vigorously and the most direct and efficient way is generating power. Collecting waste for power generation can not only dispose the idle waste protecting the environment, but also generate a part of power for sell, producing good economic benefits.

Solar energy is a kind of clean energy and also a kind of inexhaustible energy. Photovoltaic power needn't fuel consumption and erection of transmission lines into electric and energy quality is high. Under the great pressure of the fossil fuels shortages, the photovoltaic power generation industry has shown obvious advantages in economy, environmental protection and so on. In the first half of 2015, the national total of photovoltaic power generation capacity reached 19 billion kWh [3]. At the end of June, 2015, the national photovoltaic power generation capacity reached 35 million 780 thousand kilowatts.

Biogas and solar power have their respective advantages in power generation. However, due to the power generation technology is not mature yet; the two new energy power generation states are not sustained and stable. They are also easily affected by temperature and light illumination. These disadvantages affect people's proper use and large-scale market. Therefore, how to overcome these 
problems and make the two clean energies make up for each other, providing a sustained, stable and uninterrupted new power generation way is of vital importance.

The technology is made of biogas generator, solar panels, battery, controller and distribution output, in which the controller is the core component (Fig.1). The controller can monitor the working state of the solar panel and biogas generator, as well as battery level and distribution output [4]. It's able to collect various data and make an analysis, after which, it will control the circuit on and off according to the programs. The system has many salient advantages such as Real-time monitoring, intelligent judgment and automatic switching through combining solar system and biogas together. Under the condition of sufficient sunlight, the system can generate power by solar panels, meanwhile, the system can accumulate heat for biogas tank from solar energy; under the condition of insufficient sunlight, the system can generate power by biogas generator, meanwhile, the system can accumulate heat for biogas tank from waste heat. Therefore, the system can supply power steadily, which we can use not only as an auxiliary energy grid, but also as the main power supply suitable for farms, biogas users and remote areas.

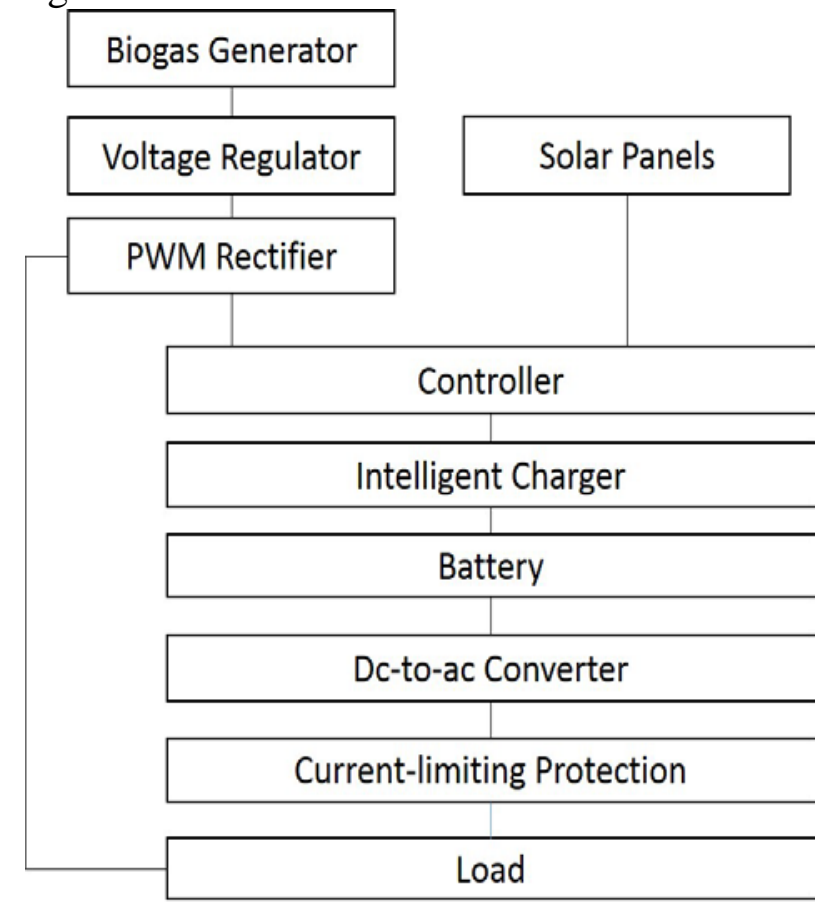

Fig.1. New energy complementary power generation system

\section{Feasibility}

Currently, most aquaculture enterprises can only use biogas in a single and traditional way because of the instability of biogas output. Diffidently, our precept above is able to overcome the instability of both solar energy and biogas [5]. So the two clean energies can make up for each other, providing a sustain power output for users. Take Baoding Xingyuan Dairy cooperatives as an example, the differences between traditional single energy generators and this precept are shown in table 1 .

Table 1 differences comparison

\begin{tabular}{lll}
\hline & Traditional way & $\begin{array}{l}\text { Our } \\
\text { precept }\end{array}$ \\
\hline $\begin{array}{l}\text { Product maintenance /Yuan } \\
\text { Waste consumption }\end{array}$ & 1200 & 800 \\
/ Cubic meters & 90 & 450 \\
Annual output/degree & 9900 & 17000 \\
Pipeline replacement cycle /year & 10 & 15 \\
"Three wastes" pollution & yes & no \\
\hline
\end{tabular}


Through above analysis, we find out our precept can help users increase 7100 degrees of electric output, 360 cubic meters of waste consumption and deduce product maintenance costs by \%33.3.Obviously, our precept is much better than traditional way whenever in economic aspect or environmental aspect [6]. Therefore, our precept has a Broad market prospects and strong ability to resist risks. Performance comparison between traditional single energy generators and our precept are shown in table 2.

Table 2 performance advantages

\begin{tabular}{|c|c|c|c|}
\hline & $\begin{array}{c}\text { Biogas } \\
\text { Generator alone } \\
\end{array}$ & $\begin{array}{l}\text { Photovoltaic } \\
\text { Panel alone }\end{array}$ & $\begin{array}{c}\text { Our } \\
\text { precept }\end{array}$ \\
\hline $\begin{array}{c}\text { Daily work time } \\
\text { /hour }\end{array}$ & 16 & 9 & 24 \\
\hline Daily output/kWh & $37-40$ & $3-4.5$ & 42 \\
\hline The sine wave & poor & fitting & fitting \\
\hline Manipulation & manual & automatic & $\begin{array}{l}\text { automatic+ Remote } \\
\text { control }\end{array}$ \\
\hline $\begin{array}{c}\text { Environmental } \\
\text { impact }\end{array}$ & $\begin{array}{l}\text { Temperature } \\
\text { fermentation }\end{array}$ & Sunlight, time, season & Weaken all above \\
\hline
\end{tabular}

According to table 2, our precept has better performance than biogas generator alone and photovoltaic panel alone, especially in power supply time and manipulation.

\section{Development Direction}

In most rural areas, especially in large and medium-sized farms that use organic waste to produce biogas. However, the efficiency is quite low and it is strongly influenced by temperature, causing inconvenience sometimes. In contrast, our percept can overcome the disadvantages, widen application field from a single family small biogas user to large biogas engineering users connected to the grid. Moreover, the flexible and effective way of application may be valuable in the following several aspects in the future.

Aimed at household power supply and no electricity areas, we analyze the efficiency of environment, biogas production, economic foundation and so on, finding that $2.5 \mathrm{~kW}$ output of photovoltaic complementary biogas power generation system is the most beneficial choice. Its cost is relatively low, as well. The power of biogas generator and the capacity of the solar panels can be adjusted according to the size of the biogas pool and local lighting conditions, providing users with a stable power supply together.

For large aquaculture enterprises, we can change the power to $5 \mathrm{kw}-15 \mathrm{kw}$. When biogas output is enough, the system can provide stable power supply for enterprises; when sunlight intensity is enough, the system can generate power from solar energy. As for the waste heat produced during the process, we use it for heating the biogas poor. Considering the extreme position, that is, when the biogas and sunlight intensity are neither satisfactory, the system can switch the power supply back to the state grid. Therefore, the system can keep users safe whatever the situation is, meanwhile the system help deduce the expense of electric [7].

Along with the advancement of national electric power reform, the electric generated from solar energy and other renewable energy is allowed to connect to the national grid. The stability and output of our system are much better than photovoltaic power generation system letting alone the huge biogas resources in our nation. Grid-connected looks really promising.

\section{Conclusion}

According to the bottleneck of the new energy's utilization, this thesis puts forward a new system. Because biogas engineering and photovoltaic power generation have different operations in different weather, we make them up for each other. When weather is cold and the biogas output is not enough, the system can generate power from solar panel, at the same time, waste heat is collected for heating the biogas pool. In a word, the system helps make full use of new energy 
and reduce resources waste.

Through the above analysis we can see that biogas and solar hybrid power generation system has broad prospects. In the future, we have to strictly control the continued development of technology and qualities, aiming at taking a big step forward, breaking the existing technical barriers and eventually making full use of new energy.

\section{Reference}

[1] Li Yan, Ying Hu Liu, Zi Li Mei ,biogas engineer situation and its prospect, Chinese biogas, 1996.

[2] Min Lin, the usage of solar energy in north cold areas, Shanxi architecture, 2010.

[3] Dan Meng, research about national new energy low capacity over production, economic, 2010.

[4] Yi Bo Zhao, latest process of new energy power generation, Electrical engineering technology, 2004

[5] Wei Niu , situation and development of national new energy power generation, Shenyang institute of engineering,2005.

[6] Hong Xing Xu, situation and countermeasure of the usage of national new energy, domestic and foreign energy, 2010

[7] Long Li, situation and prospect of domestic Photovoltaic power generation system, technology communication, 2009. 